\title{
CXC Cytokine Gene
}

National Cancer Institute

\section{Source}

National Cancer Institute. CXC Cytokine Gene. NCI Thesaurus. Code C26010.

CXC Cytokine Genes encode Alpha Chemokines, CXC-type dual-cysteine chemokines with paired cysteine residues separated by a non-cysteine residue in their primary sequence that act as chemoattractants for neutrophils, but not for monocytes. $(\mathrm{NCl})$ 